\title{
As relações entre ética, moral e comunicação em três âmbitos da experiência intersubjetiva
} The relations among ethics, moral and communication in three dimensions of the intersubjective experience

\author{
Ângela Cristina Salgueiro Marques I angelasalgueiro@gmail.com \\ Doutora em Comunicação Social pela UFMG e professora do Programa de Pós-Graduação \\ em Comunicação Social da Faculdade Cásper Líbero (SP).
}

\section{RESUMO}

Processos comunicativos ético-morais ganham concretude por meio da linguagem, em três âmbitos da experiência intersubjetiva: a troca argumentativa voltada para o entendimento e/ou soluçáo de problemas coletivos (via ampliação da percepção particular e consideração do ponto de vista dos outros); a demanda por reconhecimento social, que aproxima a auto-realização dos sujeitos de sua socialização; e a produção mediática de representaçôes que estimulam continuamente sentimentos morais voltados ao outro.

Palavras-chave: comunicação, processos ético-morais, reconhecimento social.

\section{ABSTRACT}

Ethical-moral communicative processes are instituted by language, in three spheres of the intersubjective experience: the argumentative oriented to agreement andlor solution of collective problems (with the amplification of particular perception and the consideration of the point of view offered by others); the demand for social recognition, that intersects citizens' self-realization with their socialization; and the production of media representations that continuously stimulates moral feelings towards the other.

Keywords: communication, ethical-moral processes, social recognition. 
Uma abordagem que pretende estudar as relaçóes entre processos éticomorais e a comunicação deve considerar os modos operatórios dos meios de comunicação de massa, mas também aos modos de difusão e apropriação crítica das mensagens mediáticas. Tal abordagem deve considerar também os modos como os indivíduos buscam entendimento e solução para as questóes morais que suscitam não só reflexôes ligadas ao auto-entendimento dos sujeitos mas que, a partir delas, almejam formas de negociação capazes de garantir soluçóes que contemplem as demandas da coletividade. No contexto das sociedades atuais, a busca pelo diálogo, pelo debate e pela consideração dos pontos de vista de todos coloca-se como desafio e necessidade, pois revelam as dificuldades de conectar demandas éticas de natureza subjetiva, ligadas a diferentes concepçóes de bem-viver, a demandas morais que dizem respeito a como nos relacionamos com os outros na busca de reconhecimento social. Nesse sentido, as interseçôes entre ética, moral e comunicação podem ser examindas a partir de três âmbitos distintos e intrinsecamente articulados.

O primeiro envolve a ética do discurso (ou da discussão), formulada por Habermas $(1995,1987)$ na tentativa de apontar um modo de comunicação intersubjetiva para a solução de conflitos e impasses normativos que seja livre de coerçóes e violências de toda sorte, fundada na igualdade entre parceiros de interlocuçáo que se atribuem reciprocamente o status de parceiros moralmente dignos de serem ouvidos e considerados em debates sobre questôes de interesse coletivo. A ética do discurso visa a ampliação dos horizontes éticos individuais (e não a sua supressão, como contestam muitos dos críticos de Habermas) tendo em vista a consideraçáo de questóes que dizem respeito ao que é bom para todos. Para tanto, faz-se necessário buscar maneiras de conciliar interesses e necessidades particulares, que emergem em esferas públicas parciais de interação de grupos e indivíduos, com preocupaçóes inerentes a todos aqueles que integram as sociedades atuais altamente complexas, pluralistas e diferenciadas.

Um segundo âmbito abrange as formas como os indivíduos buscam, no contexto de suas relaçôes com os outros, uma auto-realização que não depende apenas de uma reflexão interna ou do cumprimento de princípios éticos internalizados e construídos como parâmetros de avaliação das condutas individuais. Tal auto-realização não é possível, segundo Axel Honneth (2003), sem o reconhecimento social, ou seja, sem o apoio, o incentivo e a validação dos outros. No contexto da ética do discurso, o reconhecimento designa o tipo de respeito mútuo que envolve, ao mesmo tempo, a singularidade e a igualdade de todos os interlocutores. Apresentar-se diante do outro e expor argumentos e pontos de vista ao escrutínio público exige respeito, reciprocidade e uma disposição em se "colocar no lugar do outro". Contudo, o reconhecimento proposto por Honneth parte do pressuposto de que a moral não está ligada a situaçóes que julgamos boas, mas ao respeito das aspiraçóes sustentadas pelos indivíduos de modo a garantir sua integridade e o florescimento de sua identidade.

As atitudes morais devem, portanto, instaurar condiçóes para que os indivíduos possam ser reconhecidos em seus relacionamentos de amor e amizade, em suas buscas pela conquista de direitos, e em atividades nas quais suas 
habilidades são avaliadas pelo valor que possuem ou que podem oferecer a projetos coletivos. A legitimidade de categorias sociais de percepção e julgamento dos sujeitos é posta em causa quando indivíduos e grupos tematizam experiências de injustiça nas quais se sentem lesados em suas expectativas de reconhecimento. Mas a alteração e revisão das estruturas socias e cognitivas (dos esquemas de pensamento) que utilizamos para classificar e interpretar os sujeitos depende da desnaturalização de suas práticas.

Esse trabalho de tematização e crítica dos esquemas de percepção e rotulação do mundo dos outros pode contar, às vezes, com as narrativas mediáticas que, ao conferir visibilidade a "outros distantes" e às suas condiçóes de vida, alimentam sentimentos morais de responsabilidade e de solidariedade. Estes, em momentos críticos que suscitam amplos e continuados debates, podem, por sua vez, alimentar julgamentos morais voltados para a busca de processos de soluão de problemas que unam sem apagar as diferenças, que indiquem aquilo que é compartilhado entre estranhos, sem privar o outro da condição de outro, que aproximem avaliaçóes individuais de avaliaçóes coletivas conferindo à ética "o caráter de projeto democrático, fundado no diálogo, na discussão e na compreensão do outro” (ESTEVES, 2003, p.304).

Nesse sentido, o terceiro âmbito de relação entre ética, moral e comunicação é o espaço mediático. Entretanto, para uma efetiva avaliação de seus entrecruzamentos, não só suas lógicas operatórias devem ser observadas, mas sobretudo, o diálogo entre textos e audiências e as complexas relaçóes entre os enunciados mediáticos e questóes de atribuição de valor aos sujeitos. Ao refletirmos sobre a ética e a moral no contexto da comunicaçáo, náo podemos deixar de fazer duas consideraçóes principais. A primeira delas ressalta que processos ético-morais (que unem a auto-realização dos indivíduos e a realização da sociedade) dizem respeito aos modos como os media atuam e influem nas relaçôes intersubjetivas, fornecendo insumos simbólicos não só para a construção das identidades subjetivas, mas também para a ativação constante de sentimentos morais a partir da representação imagética dos "outros". A segunda consideraçáo ressalta o fato de, se de um lado os media agem estrategicamente para manter uma performance industrial competitiva, de outro eles permitem que discursos e perspectivas antes enclausurados se tornem amplamente disponíveis no tempo e no espaço. Sob esse aspecto, desempenham um papel dúbio e ambivalente: ao mesmo tempo em que selecionam e hierarquizam vozes e discursos, democratizam (tornam visíveis e disponíveis) visões e perspectivas sociais e políticas (THOMPSON, 1998; STEVENSON, 1997).

Neste texto, pretendo revelar que uma articulação entre questôes éticomorais e comunicacionais pode ser melhor entendida a partir de uma análise que leve em conta: i) a ética do discurso, ii) as demandas por reconhecimento social e iii) as representaçôes do mundo do "outro" na mídia. Essas dimensôes privilegiam, a partir de uma ótica político-filosófica, a comunicação intersubjetiva (seja ela face a face ou mediada) como aspecto central da elaboraçáo e constante transformação dos princípios ético-morais que regem os conflitos e as negociaçóes agonísticas nas sociedades contemporâneas. 
Seguindo as dimensões acima apontadas, o texto se divide em três partes. Na primeira parte, busco apontar como os indivíduos utilizam o discurso para empreeder, no espaço público de discussão, uma busca intersubjetiva pelo entendimento e por normas que contemplem os interesses e o bem coletivo. A segunda parte do trabalho dedica-se a mostrar como, nessa busca, os indivíduos são instados a se colocar no lugar dos outros (ideal role taking) e, ao fazer isso, demonstrarem reconhecimento pelo valor moral de seus interlocutores, entendendo-os como sujeitos capazes de produzir e sustentar os próprios pontos de vista, como portadores de direitos e como detentores de habilidades singulares passíveis de trazer contribuiçóes ao todo social. Por fim, na terceira parte, evidencio como a presença dos meios de comunicação nas experiências particulares e coletivas pode contribuir para o desenvolvimento moral das sociedades e dos sujeitos a partir da construção discursiva de representaçóes que circulam tanto nos âmbitos rotineiros e informais da vida cotidiana quanto em uma esfera pública articulada em rede, na qual as opiniôes e identidades podem ser reveladas, testadas e escrutinizadas.

\section{A ética do discurso e a busca intersubjetiva pelo entendimento: aproximações entre ética e moral}

Na concepção de Habermas (1987, 1995, 2004), a ética da comunicação (ou do agir comunicativo) está fundada na ampliação dos horizontes éticos individuais tendo em vista a consideração de questôes que dizem respeito ao que é bom para todos. De modo a revelar como, por meio da interação discursiva na esfera pública, os indivíduos poderiam chegar a um entendimento acerca de seus interesses e necessidades, ele procurou esboçar uma teoria, a ética do discurso, capaz de evidenciar como o uso racional da linguagem é capaz de promover o entendimento mútuo e um acordo provisório entre os participantes de discussôes práticas, as quais originam a esfera pública. Assim, nessa esfera, sujeitos capazes de fala e ação usam a linguagem e o conhecimento intuitivo de como proceder em determinadas situaçôes (adquirido no processo de socialização), de forma racional (o que não significa isenta de elementos estéticoemocionais) para que possam chegar ao entendimento, intersubjetivamente, sobre algo no mundo. A importância da linguagem na teoria habermasiana não se encontra somente nas características semânticas que ela adquire quando toma a forma de um proferimento, ou expressão. Além de entender o que o outro diz, os parceiros precisam empenhar-se em um confronto discursivo que exige "que os indivíduos escutem uns aos outros, respondam à críticas e justifiquem suas posiçóes reciprocamente, colocando-se sempre no lugar do outro" (CHAMBERS, 1996:100).

Alguns críticos de Habermas, sobretudo Thompson (1998), argumentam que tais condiçóes ideais da discussão não configuram um modelo de solução de conflitos que possa ser adaptado às circunstâncias concretas em que sujeitos plurais e fisicamente distanciados buscam negociar e solucionar dilemas morais. Soma-se a isso o entendimento de que, ao separar questôes éticas de questôes morais, Habermas estaria negando as preocupaçôes individuais 
dos sujeitos para universalizar aquilo que dificilmente pode ser generalizado: parâmetros de percepção do mundo constituídos por meio de experiências subjetivas, sejam elas positivas ou negativas (danos morais como desrespeito, violência, negação de direitos, humilhação, etc.). Acredito que esse tipo de interpretação esteja ligado a afirmaçóes ambíguas de Habermas a respeito de sua distinção entre ética e moral no contexto das interaçôes práticas dos sujeitos que negociam sobre a validade de normas que os vinculam coletivamente.

Os envolvidos nessas interaçôes precisam deixar de lado a pergunta sobre que
regulamentação é 'melhor para nós', a partir da respectiva visão que consideram 'nossa';
e só então checar, sob o ponto de vista moral, que regulamentação 'é igualmente boa
para todos' em vista da reivindicaçâo moral prioritária da coexistência sob igualdade
de direitos. (HABERMAS, 2004, p.319 e 322, grifos meus)

Três consideraçôes podem ser feitas a partir dessa citação. A primeira é a constatação de que, para Habermas, a ação comunicativa sublinha a importância da criação e manutenção de uma dinâmica argumentativa na sociedade, pois é somente por meio dela que passamos a dialogar, debater e negociar continuamente normas, valores e necessidades. O discurso (discussão) nos possibilita expressar nossos desejos, sentimentos e necessidades de modo a reconhecer quais são aqueles que pertencem ao domínio do julgamento pessoal e quais são aqueles que deveriam ser compartilhados e entendidos como pertencentes ao âmbito coletivo da justiça, das normas e dos direitos.

Nesse sentido, a segunda consideração aponta para a afirmação de Habermas de que questóes éticas e morais possuem naturezas diferentes. Segundo ele, questóes éticas são aquelas que se colocam do ponto de vista da primeira pessoa (do singular ou do plural). Elas dizem respeito a indagaçóes que buscam dar respostas a "quem sou eu e quem gostaria de ser, ou como deveria levar minha vida", ou ainda como os membros de uma comunidade "se entendem, quais os critérios segundo os quais deveriam orientar suas vidas, o que seria melhor para todos a longo prazo, etc." (HABERMAS, 2004, p.40). Já as questóes morais referem-se à busca de normas e regras capazes de permitir a coexistência em sociedades pluralistas, pautada pela busca do interesse de todos e não pelo que é melhor para todos. Assim, enquanto as questóes éticas estão voltadas para o auto-entendimento e para o que é "bom para mim ou para nós", as questóes morais se destinam a descobrir "qual a regulamentação mais adequada ao interesse equânime de todos os atingidos (sobre o que é bom, em igual medida, para todos)" (HABERMAS, 2004, p.313). A distinçáo entre ética e moral náo pode ser concebida como uma tentativa de isolamento ou apagamento da subjetividade em prol da coletividade. Habermas reafirma constantemente em seus textos que julgamentos morais só se concretizam a partir da perspectiva subjetiva dos concernidos que, ao buscarem um acordo, devem avaliar as diferentes dimensóes do problema buscando ampliar suas perspectivas e não mantê-las herméticas às consideraçóes dos outros. 


\begin{abstract}
progressiva do horizonte de interpretaçâo. A partir do horizonte de suas respectivas auto-compreensóes e compreensóes de mundo, as diversas partes em diálogo referem-se a um ponto de vista moral pretensamente partilhado, que induz a uma descentralização sempre crescente das diversas perspectivas, sob as condiçóes simétricas do discurso (e do amprender com o outro) (HABERMAS, 2004, p.316).
\end{abstract}

A ética do discurso reúne, entáo, princípios que tentam direcionar os indivíduos para a resolução cooperativa de problemas que atingem a todos. Para Habermas, as normas e regras que guiam as relaçóes humanas em sociedades altamente complexas e plurais náo podem ser mais definidas por princípios tradicionais reunidos nas narrativas religiosas e institucionais. Assim, a ética do discurso determina que uma norma só pode ser considerada válida ou justa se ela for discutida abertamente por todos os concernidos, sob condiçôes livres de quaisquer constrangimetos (HERRERO, 2002). Pautada pela equidade e paridade entre os participantes de uma discussão, a ética do discurso é um procedimento que demanda "aos participantes que reflitam e avaliem suas necessidades e interesses racionalmente do ponto de vista de sua generalidade" (CHAMBERS, 1996, p.103). Eles devem estar aptos a formular razóes próprias e passíveis de serem compreendidas e aceitas; de iniciar debates e interpretar suas necessidades de maneira reflexiva, expondo seus interesses sob uma perspectiva generalizante (MAIA, 2001; COHEN e ARATO, 1992).

Todavia, os procedimentos de generalização de perspectivas e necessidades não impóem a supressão de particularidades ou o esquecimento de dimensóes do bem-viver, mas apontam a situação discursiva como um processo moral transformativo que nos permite uma aproximação do universo do "outro", possibilitando a emergência de novos vínculos e de novos interesses. Como afirma Habermas, "se os atores não trouxerem consigo, dentro de seu discurso, suas histórias de vida individuais, suas identidades, suas necessidades e desejos, tradiçôes e pertencimentos, o discurso prático será esvaziado de todo o seu conteúdo" (1982, p.255)

Nesse sentido, os discursos não devem ser entendidos como atividades destinadas a encontrar regras que conectem diferenças isoladas, mas como práticas necessárias à compreensão de como as diferenças se sobrepóem e se interpenetram (BENHABIB, 1996).

$O$ discurso envolve mais do que um tratamento igual àqueles afetados. $O$ ponto de partida analítico da ética do discurso não é uma concepção de soberania desconectada $e$ isenta da individualidade, mas a infra-estrutura comunicativa e intersubjetiva da vida social cotidiana. Os individuos agem em relaçóes de reconhecimento mútuo nas quais adquirem e afirmam sua individualidade e liberdade de forma intersubjetiva. No processo do diálogo, cada participante articula seus pontos de vista e interpretaçóes de necessidades e desempenha papéis ideais em uma discussão prática e pública. Isso promove o quadro analítico no qual o entendimento da interpretação das necessidades dos outros se dá por meio de um insight moral e náo da empatia (COHEN e ARATO, 1992, p.376).

O diálogo, a prática concreta do discurso, envolve uma troca mútua de perspectivas na qual todos devem ser estimulados a adotar a perspectiva de seus 
interlocutores "a fim de que possam examinar a aceitabilidade de uma solução de acordo com o modo como todos os outros entendem a si mesmos e o mundo" (HABERMAS, 1990, p.98). Sob esse aspecto, o ponto de vista moral constituído pela ética do discurso não demanda um anulamento de necessidades, interesses e desejos subjetivos (como se o que fosse da ordem particular fosse egoisticamente ruim e só o que remete ao coletivo fosse bom), mas sim requer o exercício de "não olhar para nosso próprio entendimento de nós mesmos e do mundo como o padrão por meio do qual podemos universalizar um modo de ação" (HABERMAS, 1990, p.112). Se os sujeitos avaliam determinados problemas coletivos unicamente à luz de sua própria experiência particular, correm o risco de se tornarem moralistas, de querer impor seu próprio ponto de vista aos outros desconsiderando condiçôes de comunicação capazes de proporcionar o exame público e coletivo das perspectivas de cada um.

A ética do discurso proposta por Habermas, ao estabelecer conexóes entre o ponto de vista particular (das experiências e sentimentos) e o ponto de vista moral (da universalização e do coletivo) fornece as bases para a construção da teoria da ação comunicativa e da constituição do espaço público. A ação comunicativa, voltada para o entendimento recíproco dos sujeitos acerca de algo que pertence aos mundos objetivo, social e subjetivo, aponta para o modo como o discurso se transforma em elemento central da construção de decisóes capazes de, a partir da consideração pública de argumentos particulares, constituir não só uma base comum para acordos firmados em torno de elementos generalizáveis identificados, interpretativamente, a partir da avaliação coletiva de necessidades e interesses particulares.

\section{A busca por um ponto de vista moral para a avaliação dos con- flitos sociais: a teoria do reconhecimento}

O ponto de vista moral contido na ética do discurso requer que consideremos nossos interlocutores como indivíduos que merecem igual consideração e que são moralmente capazes de elaborar, defender e revisar seus pontos de vista em público (MAIA, 2001). Tais condiçóes de simetria e reciprocidade exigem "uma suspensão de situaçôes de desconfiança, duplicidade, desigualdade e subordinação" (BENHABIB, 1986, p.285). Para que todos sejam vistos como iguais e considerados como parceiros do diálogo, o discurso prático se configura como um procedimento que, ao mesmo tempo, leva em consideração os entendimentos individuais da situação em causa e estimula "os participantes a perceberem que pertencem a uma comunidade ilimitada de comunicação" (HABERMAS, 1990, p.98). Tal comunidade asseguraria redes de reconhecimento recíproco derivadas do esforço de perceber os problemas pelo olhar dos outros. $\mathrm{O}$ igual tratamento exigido nessa relação tende a procurar formas de inclusão no debate que não sejam niveladoras de diferenças, permitindo que o "outro" seja respeitado em sua alteridade. Tal determinação está no centro da ética do discurso e perpassa toda a obra de Habermas:

"Aos 16 anos, quando soube da amplidão das atrocidades cometidas pelos alemães durante a guerra, tenho buscado, ora aqui, ora ali, vestígios de uma razão que una 
sem apagar a separação, que ligue sem negar as diferenças, que indique o comum e o que é compartilhado entre estranhos, sem privar o outro da condiçáo de outro" (HABERMAS apud ANDERSON, 2001, p.7)

Ao se propor a encontrar um princípio moral do respeito indistinto por toda e qualquer pessoa e da co-responsabilidade pelas consequências de açóes e julgamentos, Habermas tenta elaborar um princípio que se desvincula de um conceito estático de sujeito, passando a tematizá-lo sempre em relação aos outros.

O reconhecimento social recíproco reflete o momento partilhado da experiência moral, na qual os indivíduos se colocam como portadores de necessidades e buscam compreensão e aprovação junto aos outros. A auto-realização dos sujeitos e a evolução moral da sociedade se entrelaçam de modo a evidenciar que, de um lado, a realização de si não pode se restringir à interpretaçáo de certos ideais de vida particulares e, de outro lado, que a sociedade deve alimentar padróes simbólicos de julgamento que, ao invés de depreciar e estigmatizar, apontem caminhos para a construção positiva de identidades individuais e coletivas.

$O$ vinculo entre a experiência de reconhecimento e a atitude do sujeito em relação a ele mesmo resulta da estrutura intersubjetiva da identidade pessoal: os individuos só se constituem como pessoas quando aprendem a se ver a partir do um ponto de vista de um outro aprovador ou encorajador, como seres dotados de qualidades e capacidades positivas (HONNETH, 2003, p.273).

A obrigação social de apresentar e representar o "eu" para o "outro" na vida cotidiana, de rastrear todas as ofensas que lhe são feitas e zelar pela reparação das ofensas inflingidas ao "eu" e ao "outro" requer uma forma de comunicação na qual os interlocutores se posicionam a partir de esquemas cognitivos e sociais para atribuir ou negar valor aos outros. Na relação comunicativa de reconhecimento mútuo prevalece o conflito, uma tensão que busca negociar quais são os parâmetros que são utilizados para atribuir um valor aos sujeitos, seja no plano das relaçóes privadas, jurídicas ou sociais.

Honneth (2003) e Fraser (1997) salientam que a busca por reconhecimento envolve o questionamento e o exame desses padrôes e códigos nos quais nos baseamos para atribuir valor aos outros. Nesse sentido, o reconhecimento está diretamente relacionado ao status social atribuído aos indivíduos, ou seja, se eles são reconhecidos como parceiros de debate moralmente capazes de formularem e sustentarem pontos de vista e posiçóes na esfera pública, ou se eles são vistos como incapazes de contribuírem para o progresso coletivo, sendo tratados como inferiores e dignos de desprezo:

Quando esses padröes constituem atores como pares, capazes de participarem em condiçóes de igualdade um com o outro na vida social, então podemos falar de reconhecimento recíproco e igualdade de status. Quando padróes institucionalizados de valor cultural constituem alguns atores como inferiores, excluidos, totalmente outros, simplesmente invisiveis, isto é, menos que um parceiro completo na interação social, então nós falaremos de falso reconhecimento e status subordinado (FRASER, 1997, p.29). 
Quando formas de desrespeito causam danos morais nos sujeitos, não só o seu auto-entendimento fica comprometido, mas suas possibilidades de uma inserção social marcada pela confiança recíproca, pelo respeito moral e pela estima social. Honneth ressalta que a vulnerabilidade dos sujeitos, ligada à implicação moral do reconhecimento mútuo, torna-se especialmente evidente quando ganhamos clareza acerca dos danos morais que "ferem as pessoas em uma compreensão positiva de si mesmas" (2003, p.213). Assim, a integridade e a identidade dos indivíduos depende do estabelecimento de padróes de relacionamento intersubjetivo capazes de assegurar assentimento, aprovação e valorização do outro.

Mas, tanto para Habermas quanto para Honneth, é a violação do reconhecimento que nos permite perceber a qualidade moral de uma situação que nos atinge. É quando a integridade física e moral de nosso próximo está em risco que sentimentos morais de solidariedade e responsabilidade podem dar origem a questionamentos e lutas por respeito e estima social:

Não iremos perseguir certos conflitos de ação como moralmente relevantes se não percebermos que a integridade de uma pessoa está sendo ameaçada ou violada. Os sentimentos formam a base de nossa própria percepção de que algo é moral. Aquele que é cego para o fenômeno moral não possui o sensor para o sofrimento de uma criatura vulnerável que tem o direito de proteção para a sua integridade fisica e sua identidade. E esse sensor está claramente relacionado com a simpatia e a empatia (HABERMAS, 1990, p.112).

Nossa habilidade de sermos capazes de criar empatia com os problemas de nossos vizinhos também depende de recursos emocionais compartilhados que não se restringem a problemas do discurso racional. Certamente, os sujeitos não alcançam sua auto-realização somente por meio do desenvolvimento de suas capacidades dialógicas para que possam trocar razōes com os outros. A realização ético-moral dos sujeitos e das sociedades nas quais se inserem também dependem "de nossa habilidade para experimentar a dor dos outros” (STEVENSON, 1997:81).

Diante disso, é interessante notar como o conteúdo dos discursos mediáticos configura-se atualmente como uma forma relevante de mostrar que as representaçóes podem estimular sentimentos morais e interesse pela experiência dos outros. E, apesar de muitas vezes essas representaçóes não desencaderem processos de reflexão prático-moral (que vâo além da empatia e da solidarizaçáo com a dor dos outros), elas atestam a possibilidadede de que a difusão de informaçóes e imagens por meio da mídia pode "ajudar a estimular e a aprofundar um sentimento de responsabilidade pelo mundo náo-humano da natureza e pelo universo dos outros distantes que náo compartilham das mesmas condições de vida que as nossas" (THOMPSON, 1998, p.227).

\section{Representações do outro na mídia: dos sentimentos morais à co-responsabilidade}

É sobre os meios de comunicação que recaem grandes expectativas ligadas ao reconhecimento, pois suas mensagens são amplamente difundidas e 
incorporadas à fala cotidiana, fornecendo assim, material não só para a construção da identidade, mas também para alimentar os conflitos simbólicos. A luta por reconhecimento, além de ser um processo de aprendizagem social é, no contexto mediático, um potencializador de demandas por inclusão de identidades desvalorizadas e tidas como "desviantes" de um padrão normativo amplamente aceito.

Vários são os temas abordados em programas mediáticos com potencial para despertar um envolvimento da audiência para além da mera empatia. Não raro, é possível constatar a emergência de uma solidariedade com os "não-iguais". Porém, muitas vezes a superficialidade do tratamento narrativo impede um maior grau de envolvimento e responsabilidade dos indivíduos que ultrapassem a fina película do entretenimento individualista. Somado a isso, imagens dramáticas podem ser manipuladas e exploradas com a finalidade de mobilizar a simpatia ou a antipatia, a perpetuação ou o questionamento de estigmas por meio da desconstrução de representaçóes criatalizadas. A dor de consciência é fugaz, pois "as práticas profissionais da mídia buscam representar as tragédias humanas globais mantendo uma distância segura entre nós e os outros (STEVENSON, 1997, p.80). Isso mostra que o sentido de responsabilidade é diferente da capacidade e da disponibilidade efetivas de agir em prol da integridade do outro. Como ressalta Thompson,

Os indivíduospodem ter uma profunda preocupaçâo pela infelicidade de outros distantes ou pela destruição do meio-ambiente global, mas dada a enorme complexidade dos processos que produziram as crises e situaçóes perigosas que enfrentamos hoje, e dada a dificuldade de intervir objetivamente nos processos que muitas vezes são pobremente entendidos, muitas pessoas podem se sentir incapazes de traduzir na prática esse sentido de preocupação (1998, p.228).

Contudo, podemos pensar nos recursos discursivos dos media como elementos integrantes de uma espécie de reabilitação da experiência ordinária, na medida em que "auxiliam a fazer com que questóes éticas se ampliem para abranger outros distantes que, embora remotos no espaço e no tempo, podem fazer parte de uma sequência interligada de açóes e suas consequências (THOMPSON, 1998, p.226).

As representações mediáticas, enquanto resultado de processos contínuos de interpretação do mundo concreto, solicitam aos indivíduos uma constante revisão do modo como avaliam, modificam e recriam seus parâmetros de avaliaçáo e julgamento de si mesmos e dos outros. Os elementos simbólicos contidos nas narrativas mediáticas, além de difundirem códigos de conveniência, contribuem para que cada vez mais os indivíduos revejam suas posiçóes frente ao julgamento alheio. Desta maneira, produçôes culturais que reúnem conhecimentos e saberes partilhados incorporam também aspectos de experiências identificadas como injustas, ou seja, práticas percebidas como geradoras de infortúnio ou desrespeito. Assim, a visibilidade proporcionada pelos media a narrativas e representaçóes associadas à modos de opressão simbólica tem a capacidade de deflagrar debates e discussóes que evidenciam questóes relativas a demandas de grupos marginalizados por reconhecimento. 
A construção de uma dimensão comunicacional ético-moral precisa de um leque diverso de perspectivas que nos lembram nossa condição humana compartilhada. Igualmente essencial é a existência de "domínios públicos nos quais nossas vozes e as dos outros possam insistentemente interrogar-se de maneira recíproca" (STEVENSON, 1997, p.84). Uma ética da comunicação deve contemplar o desejo e a necessidade de estar com o outro, de aceitar o desafio que o outro nos lança por meio de sua singularidade, de sua diferença. $\mathrm{O}$ encontro com o outro, seja na comunidade ou pela via das representaçóes mediáticas, se expressa sempre de forma agonística, na qual um indivíduo incita o outro por meio da dúvida e do estranhamento. Nesse sentido, o conceito de solidariedade associado à ética do discurso requer menos a empatia ou a semelhança com o outro, e mais uma habilidade de se identificar com o "nãoidêntico", ou seja "envolve a aceitação do outro como outro, o qual precisa ter a mesma chance de articular necessidades e argumentos" (COHEN e ARATO, 1992, p.383) a fim de chegar ao entendimento comum.

Como vimos anteriormente, a dimensão ética da discussão encontrase nos princípios de igualdade, cooperação, reciprocidade e não-coerção, os quais, nos debates práticos, auxiliam os interlocutores a se colocarem no lugar do outro, ultrapassando a dimensão individual e alcançando uma fusão de horizontes de interpretação. Essa relação entre ética e moral marca a busca da co-responsabilidade de todos, cada um a partir de suas próprias experiências, pelas consequências das açóes que asseguram um "ser com os outros" e um contexto de vida partilhado (HERRERO, 2002). Representaçóes do mundo do outro ou da dor do outro ativam constantemente sentimentos morais, os quais podem nos responsabilizar pelo bem-estar de outros, estejam eles ou não distantes no espaço e no tempo.

\section{Considerações finais}

A dimensão ética da comunicação encontra-se comumente associada ao funcionamento estratégico dos dispositivos mediáticos e à performance desempenhada por seus profissionais diante do constrangimento imposto pelos poderes associados ao Mercado e ao Estado. Embora tenhamos que levar em conta as várias ambivalências e desigualdades presentes nos modos operatórios dos meios de comunicação e de seus profissionais, é preciso considerar também que uma ética da comunicação, envolve as regras, normas e valores que regulam as práticas de interação da vida cotidiana. Neste artigo, vimos que processos comunicativos éticomorais ganham concretude em três âmbitos dessas práticas: a troca argumentativa voltada para o entendimento e/ou soluçáo de problemas coletivos; a demanda por reconhecimento social que aproxima a auto-realizaçáo dos sujeitos de sua socialização, e a produção mediática de representaçóes que mantém despertos sentimentos morais suscitados pela alteridade. Deste modo, é possível afirmar que as relaçóes entre ética, moral e comunicação não se restringem às práticas que implementam e renovam os imperativos de performatividade e eficácia dos media, mas devem levar em conta "a intercompreensão linguística: a comunicação organizada a partir da linguagem, pela qual os indivíduos se constituem socialmente enquanto sujeitos e a vida comum se torna possível" (ESTEVES, 2003, p.146). 
O encontro, mediado ou face a face, entre diferentes identidades marca a importância adquirida pela dimensão do reconhecimento social e de um processo de discussão coletiva capaz de apontar alternativas de solução para conflitos e modos de opressão e desrespeito. Este desafio requer uma percepção sensível das diferenças de opinião e de gostos, pois a ética, enquanto reflexão crítica acerca de preceitos morais, diz justamente de um questionamento, reformulação e justificação das condutas por nós adotadas em busca do bem-viver. Tal busca não se refere a uma posição unicamente individual, mas já pressupóe o encontro com o outro. A vida que cada um projeta para si tem considerar necessariamente os outros e os contextos institucionais de afirmaçáo e delineamento de nossas relaçóes. O processo ético-moral associado à comunicação depende de que esses indivíduos façam avançar a tradição por meio da criação e recriação de relaçóes intersubjetivas pautadas pelo respeito mútuo e voltadas para a promoção dos interesses coletivos, sem desconsiderar as singularidades e as demandas éticas das existências particulares. 


\section{Referências Bibliográficas}

ANDERSON, Joel. "A opressão invisível", Folha de S. Paulo, 22/07/01, Caderno Mais, pp.1-16.

BENHABIB, Seyla (ed.). Democracy and Difference - contesting the boundaries of the political. Princeton: Princeton University Press, 1996.

CHAMBERS, Simone. Reasonable Democracy - Jürgen Habermas and the Politics of Discourse. London: Cornell University Press, 1996.

COHEN, Jean; ARATO, Andrew. "Discourse Ethics and Civil Society". In: COHEN, J. ARATO, A. Civil Society and Political Theory. Cambridge: MIT Press, pp.345-420, 1992.

ESTEVES, João Pissarra. Espaço Público e Democracia: comunicação, processos de sentido e identidades sociais. Rio Grande do Sul: Unisinos, pp.143-168, 2003.

FRASER, Nancy. Justice interruptus critical reflection on the "postsocialist" condition. New York: Routledge, 1997.

HABERMAS, Jürgen. "A Reply to my Critics". In: THOMPSON, J. B., HELD, D. (eds.). Habermas: critical debates. Cambridge: MIT Press, pp.219-283, 1982.

. The Theory of communicative action: vol.II Lifeworld and system: a critique of functionalism reason. Boston: Beacon Press, 1987.

"Morality, Society and Ethics: an interview with Torben Hviid Nielsen”, Acta Sociologica, n.33, v.2, pp.93-114, 1990.

DiscourseEthics: Notesona Program of PhilosophicalJustification”. In: BENHABIB, S.; DALLMAYR, F. (eds.). The Communicative Ethics Controversy. Cambridge: MIT Press, pp.60-110, 1995.

- A Inclusão do Outro: estudos de teoria política. 2a Ed. São Paulo: Edições Loyola, 2004.

HERRERO, Francisco Javier. "Ética na construção da política". In: DOMINGUES, I. et al. (orgs.). Ética, Politica e Cultura. Belo Horizonte: Ed. UFMG, pp.69-87, 2002.

HONNETH, Axel. Luta por reconhecimento: a gramática moral dos conflitos sociais. São Paulo: Ed. 34, 2003.

MAIA, Rousiley. "Discursos Práticos e a Busca pela Ética". In: MARI, H. et al. (Org.). Fundamentos e Dimensóes da Análise do Discurso. Belo Horizonte: Núcleo de Análise do Discurso - FALE/UFMG, pp. 73-86, 2001.

STEVENSON, Nick. "Media, ethics and morality". In: McGUIGAN, Jim (ed.). Cultural methodologies. London: Sage, pp. 62-86, 1997.

THOMPSON, John. A Midia e a Modernidade: uma teoria social da mídia. Petrópolis: Vozes, 1998. 